\title{
Análise da diversidade fenotípica e genotípica de Enterococcus spp. isolados de fezes de suínos*
}

\author{
Phenotypic and genotypic diversity in Enterococcus spp. isolated from pig feces \\ Daiane Bopp Fuentefria ${ }^{1}$, Alessandra Einsfeld ${ }^{1} \&$ Gertrudes Corção $^{1,2}$
}

\begin{abstract}
RESUMO
O gênero Enterococcus está amplamente distribuído no meio ambiente e é geralmente encontrado nas fezes de animais de sangue quente. Todavia, a microbiota do trato gastrintestinal destes animais vem sofrendo alterações quanto à composição de espécies, devido ao uso de antimicrobianos. O presente trabalho teve como objetivo avaliar a diversidade de espécies e genética de Enterococcus spp. isolados de amostras de fezes de suínos. Foram encontradas quatro espécies $E$. faecalis $(\mathrm{n}=21)$, E. faecium $(\mathrm{n}=18)$, E. mundtii $(\mathrm{n}=7)$ e E. hirae $(\mathrm{n}=9)$, sendo que as duas primeiras foram as mais freqüentes. A região espaçadora intergênica $16 \mathrm{~S}-23 \mathrm{~S}$ rDNA, apresentou uma grande diversidade inter e intra-específica. E. faecalis apresentou a maior diversidade genética e $E$. hirae, a menor diversidade.
\end{abstract}

Descritores: Enterococcus, Fezes de Suínos, Diversidade Genética, Região Ribossomal Intergênica Espaçadora.

\begin{abstract}
The genus Enterococcus is widely distributed in the environment, and is generally found in feces of warm-blooded animals. However, the microbiota of the gastrointestinal tract of these animals has undergone alterations in its species composition, due to the use of antimicrobials. The objective of the present study was to evaluate the species diversity and genetics of Enterococcus spp. isolated from swine fecal samples. Four species were found: E. faecalis $(\mathrm{n}=21)$, E. faecium $(\mathrm{n}=18), E$. mundtii $(\mathrm{n}=7)$ and $E$. hirae $(\mathrm{n}=9)$, the first two being the most frequent. The 16S-23S rDNA intergenic spacer region showed high inter- and intraspecific diversity. E. faecalis showed the highest genetic diversity, and E. hirae the lowest.
\end{abstract}

Keywords: Enterococcus, Pig Feces, Genetic Diversity, Intergenic Ribosomal Spacer Region.

*Este artigo é baseado em uma dissertação de mestrado do Programa de Pós-Graduação em Microbiologia Agrícola e do Ambiente. ${ }^{1}$ Programa de Pós-graduação em Microbiologia Agrícola e do Ambiente (PPGMAA) - Universidade Federal do Rio Grande do Sul (UFRGS), Porto Alegre - RS/Brasil ${ }^{2}$ Departamento de Microbiologia, Instituto de Ciências Básicas da Saúde (ICBS), Universidade Federal do Rio Grande do Sul (UFRGS), Porto Alegre - RS/Brasil. CORRESPONDÊNCIA: G. Corção [Rua Sarmento Leite, 500, Departamento de Microbiologia, ICBS/ UFRGS, 90050-170, Porto Alegre - RS/Brasil. E-mail: corcao@ufrgs.br; FAX 0513308 4111]. 


\section{INTRODUÇÃO}

Embora os Enterococcus estejam amplamente distribuídos na natureza e apresentem um habitat bastante diversificado, como trato gastrintestinal de mamíferos, aves, répteis, insetos, plantas, água e solo [10], gêneros alimentícios, animais domésticos e esgoto [7], eles têm surgido como importantes patógenos em seres humanos [10,11]. A maioria das infecções é de origem endógena, entretanto, freqüentemente estes microrganismos são isolados de alimentos de origem animal, nos quais também são encontradas linhagens resistentes a agentes antimicrobianos. Sugere-se que estes alimentos possam ser reservatórios de Enterococcus resistentes e que os genes de resistência possam ser transferidos para humanos através da cadeia alimentar [16,19]. Estudos mostraram que não existe preferência hospedeiro-específica e que espécies de Enterococcus dispersam-se livremente entre reservatórios humanos e animais [9].

Poucos estudos avaliam a microbiota de Enterococcus intestinais de suínos, geralmente ela é representada pelas espécies E. faecalis e E. faecium, prevalentes em amostras de fezes desta natureza [14]. Outros pesquisadores encontraram uma terceira espécie, E. durans, em algumas amostras de fezes de suínos [5] e uma quantidade apreciável de E. hirae [2].

Este estudo tem por objetivo identificar espécies de Enterococcus isoladas de fezes de suínos da região da Grande Porto Alegre, realizando uma caracterização genotípica através da amplificação e clivagem da região intergênica 16S-23S do rDNA, para avaliar a diversidade genética destes isolados, a fim de enriquecer os conhecimentos sobre os Enterococcus associados a suínos.

\section{MATERIAL E MÉTODOS}

\section{Isolamento e identificação fenotípica dos isolados.}

As amostras de fezes (25 gramas) foram suspendidas em $250 \mathrm{~mL}$ de solução salina $(0,9 \%)$ e semeadas em Caldo Azida. Após 24h de incubação, de cada tubo com crescimento bacteriano foram retiradas nove alíquotas e inoculadas em nove placas de ágar $\mathrm{KF}$, as quais foram incubadas por $48 \mathrm{~h}$ a $37^{\circ} \mathrm{C}$. As colônias amareladas, esbranquiçadas e punctiformes foram testadas para coloração de Gram e as que apresentaram cocos Gram positivos foram inoculadas em ágar PSE por $48 \mathrm{~h}$ a $37^{\circ} \mathrm{C}$. As colônias de coloração marrom foram retiradas e armazenadas em ágar inclinado, para posterior identificação de gênero e espécie, utilizando as seguintes provas morfológicas e bioquímicas [5]: coloração de Gram, catalase, hidrólise da esculina, crescimento em caldo simples a $45^{\circ} \mathrm{C}$, crescimento em presença de 6,5\% de $\mathrm{NaCl}$, hidrólise do L-pirrolidonil, b-naftilamida, fermentação de arabinose, rafinose e manitol, utilização de $1 \%$ de piruvato, motilidade, produção de arginina descarboxilase e de pigmento amarelo.

\section{Extração de DNA cromossomal.}

As células bacterianas foram crescidas em $10 \mathrm{~mL}$ de caldo BHI por $18 \mathrm{~h}$ a $37^{\circ} \mathrm{C}$ com agitação constante de $100 \mathrm{rpm}$ [6]. Dentre as espécies, foram selecionados, aleatoriamente, para a análise molecular, 15 isolados de E. faecalis, 17 isolados de E. faecium, 7 isolados de E. mundtii e 9 isolados de E. hirae, totalizando 41 isolados.

\section{PCR-ITS.}

Os fragmentos de DNA da região intergênica 16S-23S foram amplificados utilizando-se dois oligonucleotídeos iniciadores: 5'- CCCGAAGTCGGTG ARGTAAC e 5'- CCTTCATCGGCTCCTAGTGC desenhados a partir do alinhamento de seqüências do rDNA de Enterococcus (Acession number Y18161, AJ420805, AJ420802, AJ420799, X79341). As reações foram realizadas com 2,5 mM de $\mathrm{MgCl}_{2}, 0,2$ mM de dNTP's, 1ì de cada oligonucleotídeo, 1U de Taq DNA polimerase e 200-400 ng de DNA bacteriano em um volume final de reação de 35ìl. As condições de reação foram: um ciclo inicial a $94^{\circ} \mathrm{C}$ por $2 \mathrm{~min}$, seguido de 30 ciclos a $94^{\circ} \mathrm{C}$ por $1 \mathrm{~min}$, $51^{\circ} \mathrm{C}$ por $1 \mathrm{~min}$ e $72^{\circ} \mathrm{C}$ por $1 \mathrm{~min}$, e um ciclo final a $72^{\circ} \mathrm{C}$ por $10 \mathrm{~min}$. O produto da PCR foi analisado em gel de poliacrilamida não-desnaturante $8 \%$, corado com brometo de etídeo, visualizado sob luz ultravioleta e fotografado com câmera digital Kodak 1D (versão 3.5.2). A análise do tamanho dos fragmentos foi realizada através do programa KODAK 1D (versão 3.5.2).

\section{RFLP-PCR.}

Uma alíquota de 10 ìl do amplicon foi tratada com $1 \mathrm{U}$ de Sau3AI por $2 \mathrm{~h}$ a $37^{\circ} \mathrm{C}$, conforme especificações do fabricante. Após incubação, o DNA foi submetido à eletroforese em gel de poliacrilamida não-desnaturante $8 \%$, corado com brometo de etídeo, visualizado sob luz ultravioleta e fotografado com câmera digital Kodak 1D (versão 3.5.2). A análise do 
tamanho dos fragmentos foi realizada através do cálculo de regressão de potência, com um coeficiente de correlação $r=-0,98$.

\section{Análise dos dados.}

Os dados do RFLP-PCR foram transformados em uma matriz binária, considerando-se 0 para ausência e 1 para a presença de um determinado fragmento. As matrizes de similaridade foram construídas utilizando o coeficiente de Dice e os dendrogramas construídos pelo método UPGMA; estas análises foram realizadas com o programa SPSS (versão 11.0). $\mathrm{O}$ índice de Shannon-Weaver para diversidade entre as espécies foi calculado utilizando a fórmula $\mathrm{H=Cl}$ $N\left(N \times \log N-\right.$ Ó $\left.n_{i} \times \log n_{i}\right)$, onde $n_{i}$ corresponde ao número de isolados com o mesmo perfil Sau3AI, $N$ corresponde ao número total de isolados e $C$ uma constante com valor igual a 2.3 .

\section{RESULTADOS}

Foram identificados 55 isolados como pertencentes ao gênero Enterococcus. De acordo com os testes bioquímicos e morfológicos, as espécies encontradas foram: E. faecalis $(\mathrm{n}=21)$, E. faecium $(\mathrm{n}=18)$, E. mundtii $(\mathrm{n}=7)$ e E. hirae $(\mathrm{n}=9)$.

A amplificação da região intergênica gerou dois fragmentos, com tamanhos variando de 355 a $590 \mathrm{pb}$, que geraram 14 perfis entre as diferentes espécies de Enterococcus analisadas. Fragmentos maiores que $700 \mathrm{pb}$ foram desconsiderados por serem resultado de amplificação inespecífica. A partir das matrizes de similaridade da análise da PCR-ITS, houve a formação de 5 grupos em um nível de similaridade maior que $70 \%$. O grupo 1 foi formado por isolados das quatro espécies analisadas, com a predominância de E. mundtii e de H. hirae. O grupo 2 foi formado exclusivamente por isolados de E. hirae, agrupados em similaridades maiores que $80 \%$. O grupo 3 foi formado com isolados de E. faecalis e $E$. faecium, foi o grupo geneticamente mais homogêneo com similaridade maior que $80 \%$. O grupo 5 foi formado exclusivamente por isolados de E. faecalis. Todos os isolados de E. hirae situaram-se nos grupos 1 e 2, agrupados com similaridades de 53 a $100 \%$.

A clivagem da região intergênica com Sau3AI foi realizada para avaliar a variabilidade e a diversidade genética entre os isolados na seqüência de nucleotídeos amplificada. A clivagem gerou 22 fragmentos, com tamanhos variando de 85 a $470 \mathrm{pb}$. O índice de Shannon-Weaver para diversidade genética, calculado a partir da clivagem com Sau3AI, foi 2,07 para E. faecalis, 2,09 para E. faecium, 1,94 para $E$. mundtii e 1,90 para E. hirae.

\section{DISCUSSÃO}

A espécie encontrada com maior freqüência foi E. faecalis seguida de E. faecium. Estas espécies são encontradas tanto em humanos como em animais e, geralmente, são também as mais encontradas em alimentos e no meio ambiente [7,8,9,15]. Alguns autores afirmaram, em estudos da década de 90 que, embora estas espécies possam ser encontradas em bovinos, suínos, caprinos e eqüinos, geralmente eram as menos prevalentes [9]. As espécies E. hirae e $E$. cecorum foram relatadas como prevalentes no intestino de suínos; e E. hirae, como a espécie patogênica em suínos [2].Todavia, nos últimos anos, houve uma alteração deste cenário. Em uma análise da cadeia de produção de produtos alimentícios de origem suína, E. faecalis e E. faecium foram também as espécies predominantes [15]. O mesmo ocorreu em um estudo com amostras de intestinos de peixes criados em fazendas integradas [13].

A alta variabilidade das seqüências ITS pode ser utilizada para identificação de linhagens, porém, não se extende para a rápida identificação da espécie, em função da ausência de um padrão de identificação [17]. Como cada um dos fragmentos principais representa a região ITS entre uma cópia $16 \mathrm{~S}$ rDNA e uma cópia 23S rDNA, os resultados sugerem que essas linhagens possuem pelo menos duas ou mais formas de ITS distintas, as quais diferem no tamanho e, talvez, na sua composição de nucleotídeos. A razão para essa heterogeneidade ainda não está esclarecida. Talvez seja em função do número de cópias de tRNA localizados na região ITS [3, $12,18]$.

O índice de Shannon-Weaver revelou que entre as espécies estudadas, E. faecalis apresentou a maior diversidade genética e E. hirae, a menor diversidade genética. Este maior índice de diversidade pode estar relacionado com uma maior plasticidade do microrganismo em relação ao ambiente e aos diferentes hospedeiros.

\section{CONCLUSÃO}

No presente estudo, as espécies E. faecalis e E. faecium foram encontradas com maior freqüência e apresentaram a maior diversidade genética. 
Possivelmente, dentro deste gênero, são as espécies mais disseminadas no ambiente e com uma grande capaci-dade adaptativa. A amplificação da região intergênica 16S-23S do rDNA mostrou um alto grau de variabilidade, não permitindo a separação dos isolados de acordo com a espécie.
Agradecimentos. Este estudo foi financiado pelo CNPq (Conselho Nacional de Pesquisa) e pela CAPES (Conselho de Aperfeiçoamento do Ensino Superior). Agradecemos a Prof. Dra. Marisa Ribeiro de Itapema Cardoso, Departamento de Medicina Veterinária Preventiva da Faculdade de Veterinária, UFRGS, pelo fornecimento das amostras de fezes de suínos.

\section{REFERÊNCIAS}

1 Devriese L. A., Hommez J., Pot B. \& Haesebrouck F. 1994. Identification and composition of the streptococcal and enterococcal flora of tonsils, intestines and faeces pigs. Journal of Applied Bacteriology. 77: 31-36.

2 Devriese L. A; Van De Kerckhove A, Kilpper-Balz R. \& Schleifer, K. H. 1987. Characterization and identification of Enterococcus species isolated from the intestines of animals. International Journal of Systematic Bacteriology 37: 257259.

3 Dolzani L., Tonin E., Lagatolla C., Prandin L. \& Monti-Bragadin C. 1995. Identification of Acinetobacter isolates in the A. calcoaceticus - A. baumannii complex by restriction analysis of the 16S-23S rRNA intergenic-spacer sequences. Journal of Clinical Microbiology. 33: 1108-1113.

4 Facklam R.R. \& Collins M.D. 1989. Identification of Enterococcus species isolated from human infections by a conventional test scheme. Journal of Clinical Microbiology. 27: 724-734.

5 Fuller R., Newlan M.G.M., Briggs C.H.E., Braude R. \& Mitchell K.G. 1960. The normal intestinal flora of the pig. IV. The effect of dietary supplements of penicillin, chlortetracycline or copper sulphate on the faecal flora. Journal of Applied Bacteriology 23: 195-205.

6 Givers D., Huys G. \& Swings J. 2001. Applicability of rep-PCR fingerprinting for identification of Lactobacillus species. FEMS Microbiology Letters. 205: 31-36.

7 Hammereum A.M., Fussing V., Aarestrup F.M. \& Wegener H.C. 2000. Characterization of vancomycin-resistant and vancomycin-susceptible Enterococcus faecium isolates from humans, chickens and pigs by RiboPrinting and pulsed-field gel electrophoresis. Journal Antimicrobial Chemotherapy 45: 677-680.

8 Jurkoviè D., Krišková L., Sojka M., Takaèová M., Dušinský R., Krajèoviè J., Vandamme P. \& Vancanneyt M. 2007. Genetic diversity of Enterococcus faecium isolated from Bryndza cheese. International Journal of Food Microbiology 116: 82-87.

9 Leclerc H., Devriese L. A. \& Mossel D. A. A. 1996. Taxonomical changes in intestinal (faecal) enterococci and streptococci: consequences on their use as indicators of faecal contamination in drinking water. Journal of Applied Bacteriology. 81: 459-466.

10 Morrison D., Woodford N. \& Cookson, B. 1997. Enterococci as emerging pathogens of humans. Journal of Applied Microbiology. Symposium Supplement. 83: 89S-99S.

11 Murray B. E. 1991. New aspects of antimicrobial resistance and the resulting therapeutic dilemmas. Journal of Infectious. Disease. 163: 1184-1194.

12 Naïmi A., Beck G. \& Branlant C. 1997. Primary and secondary structures of rRNA spacer regions in enterococci. Microbiology. 143: 823-834.

13 Petersen A. \& Dalsgaard A. 2003. Species composition and antimicrobial resistance genes of Enterococcus spp., isolated from integrated and traditional fish farms in Thailand. Environmental Microbiology. 5(5): 395-402.

14 Pourcher A.M., Devriese L.A. Hernandez J.F. \& Delattre J.M. 1991. Enumeration by a miniaturized method of Escherichia coli, Streptococcus bovis, and Enterococcus as indicators of the origin of faecal pollution of waters. Journal of Applied Bacteriology 70: 525-530.

15 Rizzoti L., Simeoni D., Cocconcelli P., Gazzola S., Dellaglio F. \& Torriani S. 2005. Contribution of enterococci to the spread of antibiotic resistance in the production chain of swine meat commodities. Journal of Food Protection. 68 (5): 955 $-965$

16 Roberts M. C. 1996. Tetracycline resistance determinants: mechanisms of action, regulation of expression, genetic mobility and distribution. FEMS Microbiology Review. 19:1-24. 
Fuentefria D.B., Einsfeld A. \& Corção G. Análise da diversidade fenotípica e genotípica de Enterococcus spp. isolados de fezes de suínos

17 Ruiz A., Poblet M., Mas A. \& Guillamón J. M. 2000. Identification of acetic bacteria by RFLP of PCR-amplified 16S rDNA and 16S-23S rDNA intergenic spacer. International Journal of Systematic and Evolutionary Microbiology. 50: 19811987.

18 Sechi L.A. \& Daneo-Moore L. 1993. Characterization of intergenic spacers in Two Operons of Enterococcus hirae ATCC 9790. Journal of Bacteriology. 175: 3213-3219.

19 Thal, L. A., Chow J. W., Mahayni R., Bonilla H., Perri M. B., Donabedian S. A., Silverman J., Taber S. \& Zervos, M. J. 1995. Characterization of antimicrobial resistance in enterococci of animal origin. Antimicrobial. Agents Chemotherapy. 39: 2112-2115.

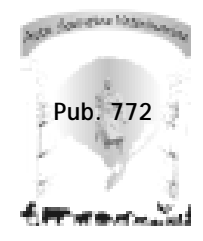

